American J. of Engineering and Applied Sciences 4 (1): 89-92, 2011

ISSN 1941-7020

(C) 2010 Science Publications

\title{
Elastic-Plastic Non Linear Behaviors of Suddenly Loaded Structures
}

\author{
Assal Tehseen Hussein \\ Department of Civil Engineering, College of Engineering, University of Diyala, Iraq
}

\begin{abstract}
Problem statement: The adaptively shifted integration technique was applied to the elasticplastic analysis of framed structures under dynamic loading. Approach: This study used analysis of linear beam element, the reshifting of the of the integration points in the element is conducted in order to attain higher accuracy. Results: In nonlinear finite element analysis by the ASI technique, the highest computational efficiency has been achieved by shifting the numerical integration points for evaluation of stiffness matrices of linear Timoshenko beam element. A computer program has been Written by VBASIC for solve the problem of the steel frame, results of numerical examples demonstrate the validity of the computer program and study many parametric study, such as Time step and Mass of the structure. Conclusion/Recommendations: In the elastic analysis there is no distinction between the ASI technique and the conventional finite element method, but for elasticplastic nonlinear analysis under dynamic load Adaptive Shifted Integration (ASI) technique is capable of predicting with reasonable accuracy the behavior of steel frame structures.
\end{abstract}

Key words: Elastic-plastic analysis, non-linear, suddenly load, ASI technique, framed structures, numerical integration point, increment vector, Finite Element Method (FEM)

\section{INTRODUCTION}

The progressive collapse of World Trade Center towers in New York, USA revealed the structural vulnerability of tall steel buildings to the impact of a fast moving object. Technical investigations are necessary to clarify the technical conditions that contributed to the progressive collapse and to improve the ways buildings are designed, constructed, maintained and used. And numerical simulation is considered to be one of the means to investigate such problems.

Finite Element Method (FEM), which is based on continuum material equations, has been successfully applied to a wide range of engineering problems including structural analyses of large-scale structures (Biggs and Biggs, 1964; Ross, 1996; Šilih et al., 2008; Souiyah et al., 2009; Toi and Isobe, 1993; 1996). Generally, it is difficult to determine the loads resulted in the structures due to dynamic load and applying dynamic loads to an analytical model in the form of nodal forces may not well simulate the dynamic phenomenon. In this study, the formerly developed Adaptively Shifted Integration ASI technique for the linear Timoshenko beam element is used. The ASI technique gives a more precise solution than the conventional finite element method and has become able to simulate dynamic behaviors with strong nonlinearities by a small number of elements. From the above, it is confirmed that the ASI technique is an efficient method for analyses of frame structures both in elastic and elasto-plastic range (Lynn and Isobe, 2007).

\section{MATERIALS AND METHODS}

Adaptively Shifted Integration (ASI) technique: Elasto-plastic analyses of framed structures using the linear Timoshenko beam element are based on the following incremental form of the principle of virtual study (Lynn and Isobe, 2007).

$$
\delta \mathrm{V}-\delta \mathrm{W}=\int_{-\mathrm{L} / 2}^{\mathrm{L} / 2}\{\delta \Delta \varepsilon\} \mathrm{T}\{\Delta \sigma\} \mathrm{dz}-\{\delta \Delta \mathrm{u}\} \mathrm{T}\{\Delta f\}=0
$$

In Eq. $1, \delta \mathrm{V}$ and $\delta \mathrm{W}$ are the internal work and the external work respectively. $\{\Delta \varepsilon\},\{\Delta \sigma\},\{\Delta \mathrm{u}\}$, and $\{\Delta \mathrm{f}\}$ are the generalized strain increment vector, the generalized stress (resultant force) increment vector, the nodal displacement increment vector and the external force increment vector, respectively. The symbols $\delta$ and $\Delta$ denote variation and increment.

The relation between the generalized strain increment and nodal displacement increment vectors are given by the following equation:

$$
\{\Delta \varepsilon\{\mathrm{r})\}=[\mathrm{B}(\mathrm{s})]\{\Delta \mathrm{u}\}
$$

Here, $[\mathrm{B}(\mathrm{s})]$ is the generalized strain-nodal displacement matrix. $\mathrm{s}$ is the location of the numerical integration point and $r$ the location where stresses and strains are actually evaluated. $\mathrm{s}$ is a non-dimensional quantity, which is takes a value between 1 and 1 . It should be noted here that the linear Timoshenko beam element uses one-point integration to avoid shear locking. 


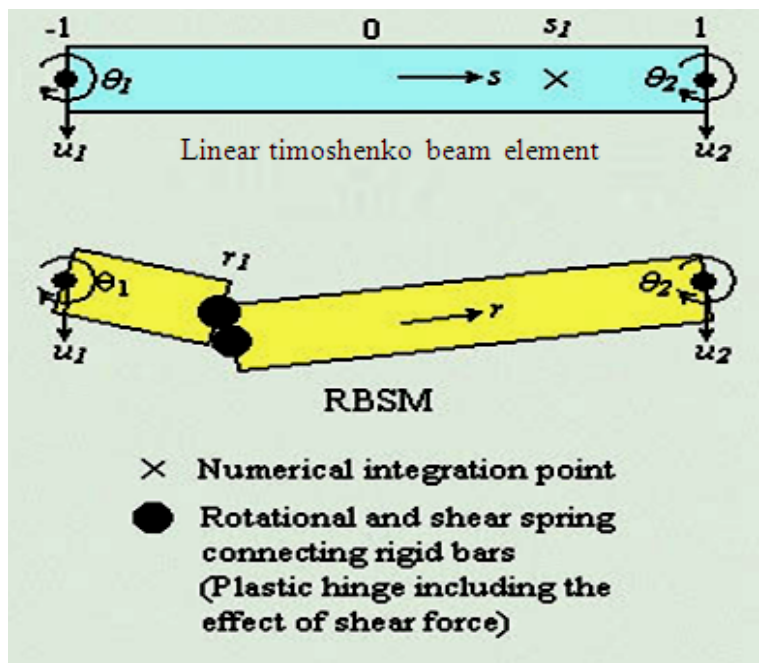

Fig. 1: Linear Timoshenko beam element and its physical equivalent

When the element behaves elastically, the relation between resultant force increment vector and generalized strain increment vector is given by the following equation:

$\{\Delta \sigma(\mathrm{r})\}=[\operatorname{De}(\mathrm{r})]\{\Delta \varepsilon\{\mathrm{r})\}$

Here, [De] is the stress-strain matrix for elastic deformation. [De] will change to [Dp], when plastic deformation is determined by the plastic flow theory using the following form of yield function:

$f \mathrm{y}(\sigma(\mathrm{r}))-1=0$

Substitution of Eq. 2-3 into Eq. 1 leads to the following form of elemental stiffness matrix:

$[\mathrm{K}]=\mathrm{L}[\mathrm{B}(\mathrm{s})] \mathrm{T}[\mathrm{De}(\mathrm{r})][\mathrm{B}(\mathrm{s})]$

In the ASI technique, numerical integration points are shifted immediately after the formation of a fully plastic section in the element in order to form a plastic hinge exactly at that section. When a plastic hinge is judged to be unloaded, the corresponding numerical integration point is Shifted back to its normal position. Here, the normal position means the location where the numerical integration point is placed when the element acts elastically.

Figure 1 shows a linear Timoshenko beam element and its physical equivalence to a Rigid-Body-SpringModel (RBSM). As shown in Fig. 1 the relationship between the locations of the numerical integration point and the stress evaluation point where a plastic hinge is actually formed is expressed as follows:

$\mathrm{r} 1=-\mathrm{s} 1$

$\mathrm{s} 1=-\mathrm{r} 1$

When the entire region of an element behaves elastically, the numerical integration point is placed at the midpoint of the element $(\mathrm{s} 1=0)$ which gives $\mathrm{r} 1=0$ from Eq.(6) in this case, the elemental stiffness matrix for the element is given by the following equation:

$[\mathrm{K}]=\mathrm{L}[\mathrm{B}(0)] \mathrm{T}[\mathrm{De}(0)][\mathrm{B}(0)]$

The generalized strain increment vector $\{\Delta \varepsilon(0)\}$ and the resultant force increment $\{\Delta \sigma(0)\}$ are calculated as follows:

$\{\Delta \varepsilon(0)\}=[\mathrm{B}(0)]\{\Delta \mathrm{u}\}$

$\{\Delta \sigma(0)\}=\left[\mathrm{D}_{\mathrm{e}}(0)\right]\{\Delta \varepsilon(0)\}$

After the formation of a fully plastic section, the numerical integration point is shifted immediately to a new point $(\mathrm{s} 1=-\mathrm{r} 1)$. For instance, if a fully plastic section occurs at the right end of an element $(\mathrm{rl}=1)$, the numerical integration point is shifted to the left end $(\mathrm{s} 1=-1)$ and vice versa. In this case, the elemental stiffness matrix, the generalized strain and resultant force increment vectors are given as follows:

$[\mathrm{K}]=\mathrm{L}[\mathrm{B}(\mathrm{s} 1)] \mathrm{T}[\mathrm{Dp}(\mathrm{r} 1)][\mathrm{B}(\mathrm{s} 1)]$

$\{\Delta \varepsilon(\mathrm{r} 1)\}=[\mathrm{B}(\mathrm{s} 1)]\{\Delta \mathrm{u}\}$

$\{\Delta \sigma(\mathrm{r} 1)\}=[\mathrm{Dp}(\mathrm{s} 1)]\{\Delta \varepsilon(\mathrm{r} 1)\}$

Here, $[\mathrm{Dp}]$ is the stress-strain matrix for plastic deformation.

\section{RESULTS AND DISCUSSION}

\section{Numerical examples:}

Example 1: Steel frame with properties shown in Fig. 2 is subjected to dynamic load $100 \mathrm{Kip}$, using these data as input data for computer program. From results of computer program, Fig. 3 shows the elastic-plastic response of the frame by using ASI technique and Fig. 4 shows the time sequence of occurrence of plastic hinges. 
Am. J. Engg. \& Applied Sci., 4 (1): 89-92, 2011

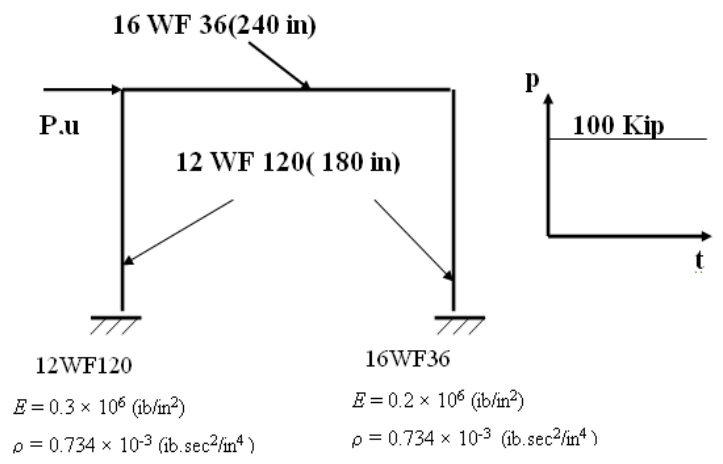

Fig. 2: Properties of Steel frame

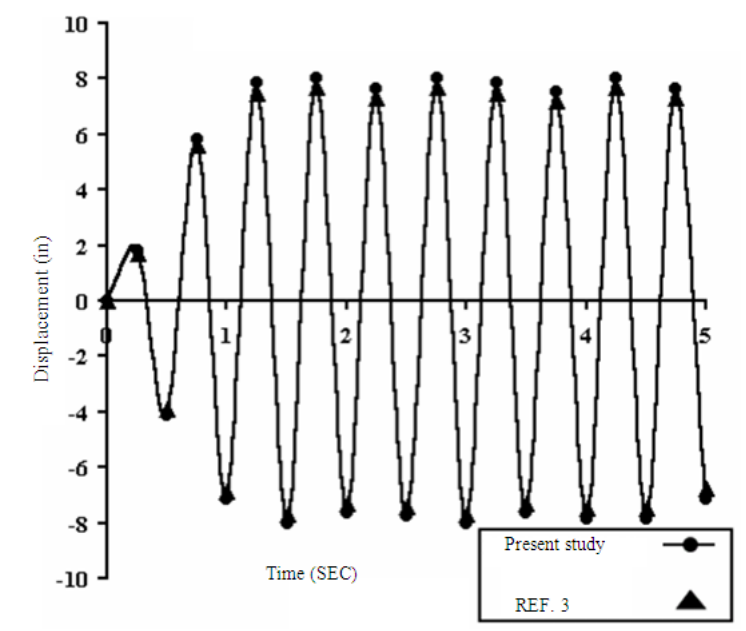

Fig. 3: Elastic-plastic response for steel frame

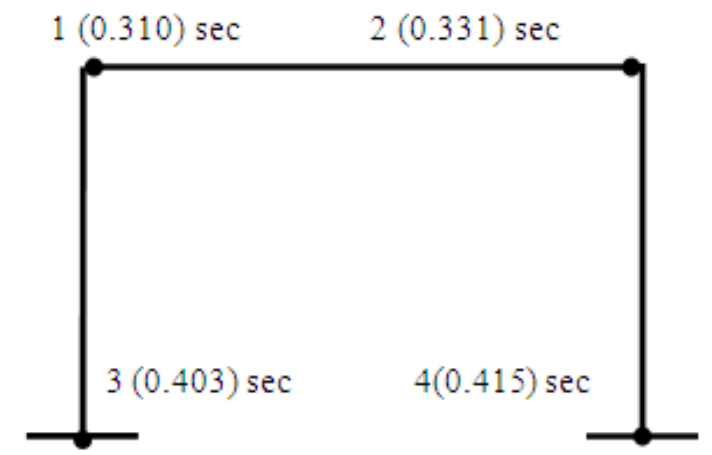

Fig. 4: Time sequence of occurrence of plastic hinge

Parametric study: The main purpose of the present study is to investigate the effect of several important parameters on the behavior of simple frame subjected to dynamic loads by using the ASI technique. The frame described in Fig. 4 is chosen to perform this investigation.

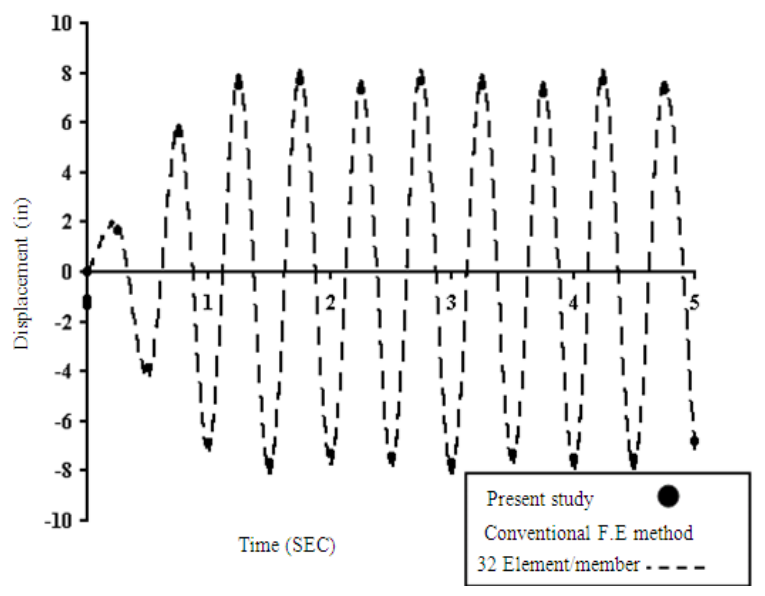

Fig. 5: Comparation between ASI technique and conventional method

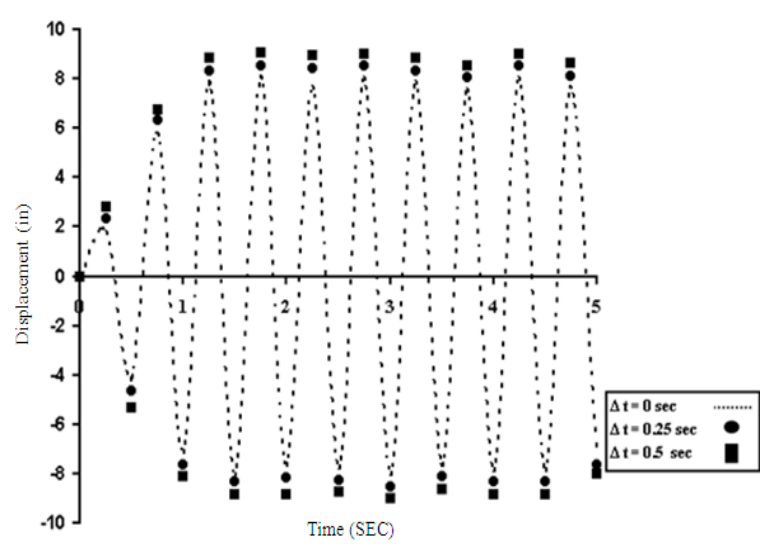

Fig. 6: Elastic-plastic response for steel frame with various time step

Accuracy of ASI technique: Figure 5 shows elasticplastic response of a frame using both ASI technique and conventional method. These results show that the oneelement per member by the ASI technique is enough to fit the results, compared with the 32-element per member approximation by the conventional method.

Time step: Figure 6 shows the elastic-plastic response of a frame for various time step length. The response indicates that a good accuracy can also be obtained even with large values of time step length.

Mass of the structure: Figure 7 shows the elasticplastic response of a steel frame for various cross sections of structure. It is observed that when the mass of structure increases, the displacement response decreases. 


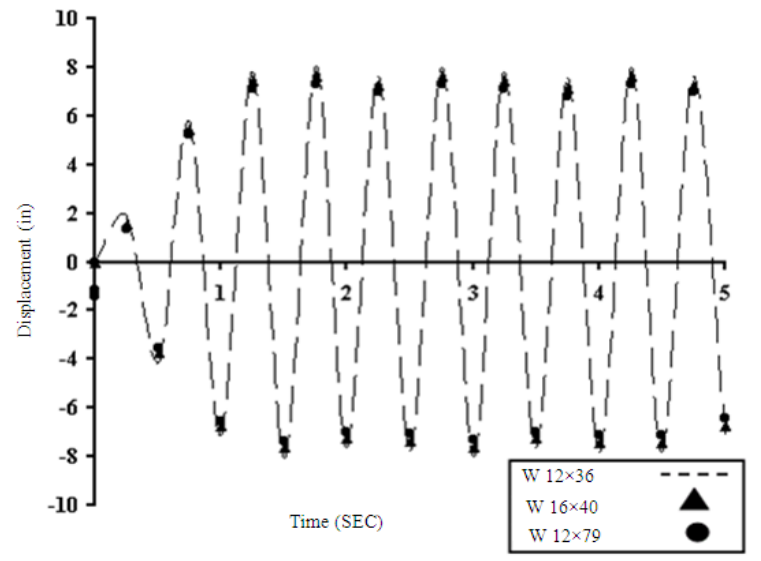

Fig. 7: Effect Mass of structure on elastic-plastic response for steel frame

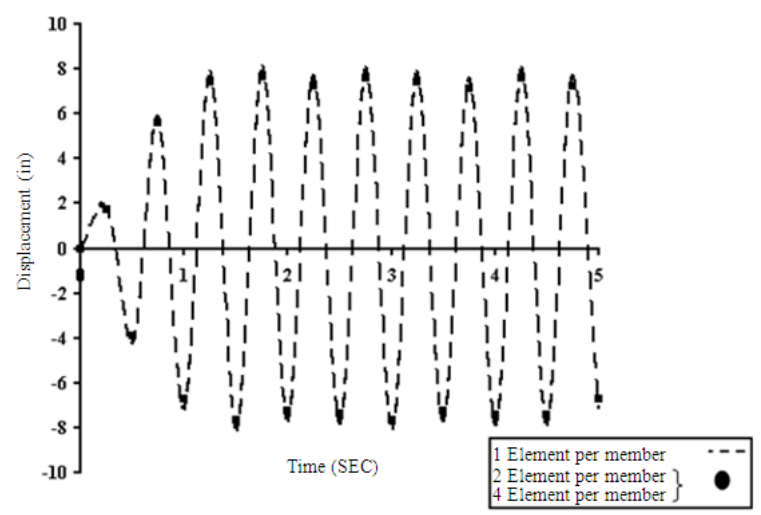

Fig. 8: Converged Solution for ASI Technique even when use low number of Element per Member

Converged solution: Figure 8 shows the elastic-plastic response of a frame for one, two and four elements per member. It is observed that the ASI technique give results with high accuracy at very low calculation cost even when element per member is very few.

\section{CONCLUSION}

In the elastic analysis there is no distinction between the ASI technique and the conventional finite element method.

This investigation has shown that the Adaptive Shifted Integration (ASI) technique for elastic-plastic nonlinear analysis under dynamic load is capable of predicting with reasonable accuracy the behavior of steel frame structures.

The ASI technique is able to cope with dynamic behaviors with strong nonlinearities including member fracture.

The strong nonlinearity problems, in which complicated analysis processes are needed in the conventional finite element analysis, can be easily analyzed by implementing the ASI technique to the finite element codes utilizing the linear Timoshenko beam element.

The one-element per member solution by ASI technique is compared with the results of the 32element per member approximation searched by the conventional finite element method. The ASI technique is more economical.

The mass of the structure was found to be an important parameter in determining elastic-plastic response of steel frame. It is observed that when the mass of structure increases $3.87 \%$ the displacement response decreases $(0.5-0.6 \%)$.

In the elastic-plastic analysis, it was found that ASI technique needs not more than two elements per member to get the exact solution, more elements will not refine the solution.

The ASI technique gives results with high accuracy at very low calculation cost even when the number of elements per member is very low.

\section{REFERENCES}

Biggs, J.M. and J.M. Biggs, 1964. Introduction to Structural Dynamics. 1st Edn., McGrew-Hill, New York, ISBN-10: 0070052557, pp: 341.

Lynn, K.M. and D. Isobe, 2007. Structural collapse analysis of framed structures under impact loads using asi-gauss finite element method. Int. J. Impact. Eng., $\quad 34: \quad 1500-1516 . \quad$ DOI: 10.1016/j.ijimpeng.2006.10.011

Ross, C.T.F., 1996. Finite Element Techniques In Structural Mechanics. 1st Edn., Albion Pub., Chichester, ISBN-10: 189856325X, pp: 207.

Šilih, S., T. Žula, Z. Kravanja and S. Kravanja, 2008. MINLP optimization of mechanical structures. Am. J. Applied Sci., 5: 48-85. DOI: 10.3844/ajassp.2008.48.54

Souiyah, M., A. Muchtar, A. Alshoaibi and A.K. Ariffin, 2009. Finite element analysis of the crack propagation for solid materials. Am. J. Applied Sci., 6: 1396-1402. DOI: 10.3844/ajassp.2009.1396.1402

Toi, Y. and D. Isobe, 1993. Adaptively shifted integration technique for finite element collapse analysis of framed structures. Int. J. Numerical Met. Eng., $\quad 36$ : 2323-2339. $\quad$.DOI: $10.1002 / \mathrm{nme} .1620361402$

Toi, Y. and D. Isobe, 1996. Finite element analysis of quasi-static and dynamic collapse behaviors of framed structures by the adaptively shifted integration technique. Comput. Struct., 58: 947-955. DOI: 10.1016/0045-7949(95)00195-M 